\title{
Breastfeeding and infant and child mortality, in Amagoro Division of Busia District, Kenya
}

\author{
Priscilla A. AKWARA
}

\section{ABSTRACT}

This study examined the impact of breastfeeding duration and age at supplementation on infant and child mortality. Data was collected for both open and closed intervals from women aged 15-49 years and resident in Amagoro Division, Busia District, western Kenya. The study found that breastfeeding initiation is quite high, with an average of $99 \%$ of the women initiating breastfeeding. The duration of breastfeeding is long, with the majority of the women breastfeeding for 19-24 months. The major problem noted in the study is early supplementation. By the age of 3-4 months about $70 \%$ of children in the open and closed intervals were already being fed on other diets in addition to breast milk. The study also found that, for both the open and closed intervals, breastfeeding duration, age at supplementation, work status of the mother, type of toilet facility used by the household, and immunizations received by the child were significant in child survival. The major conclusion derived from the results of the study is that breastfeeding practices, environmental factors, and socio-economic factors are very significant in influencing infant and child deaths. However, the impact of breastfeeding and age at supplementation are greatly modified by environmental and socio-economic factors. The study therefore recommends the re-education of health personnel, especially those in the Maternal and Child Health clinics $(\mathrm{MCH})$, on the importance of breastfeeding and proper age at supplementation for the children. The paper also recommends that female employment opportunities and female education be increased, since maternal education highly determines the work status of the mother and the nutritional, health care and sanitary conditions of the household.

\section{INTRODUCTION}

In many traditional societies, women breastfeed their children for extended periods. Prolonged breastfeeding is said to have the effect of safeguarding the health of the child (Buchanan, 1975). Several clinical and epidemiological studies have shown that mother's milk has at least three properties which help to protect the health of infants. First, it is nutritious. Breast milk appears to meet the nutritional requirements for the normal growth of an infant for at least six months (Wray, 1978). Consumed in sufficient quantities, it provides protection against malnutrition syndromes such as kwashiorkor and marasmus (Kleinman, 1984). The absence of breastfeeding is related to an excess in incidence of diseases, such as diarrhoea and gastrointestinal infections, that are exacerbated by malnutrition (Barros and Victora, 1990). Although many substitutes contain a substantial proportion of the basic nutrients, none are as rich or complete as mother's milk. Second, breast milk contains immune protein substances that serve to prevent both infections of the intestinal system and those of a more general character which enter the host through the intestinal tract. Finally, mother's milk is a sterile fluid containing substances that prevent the growth of bacteria. All these factors make breast milk a highly hygienic product.

The benefits from some of these properties, particularly the first two, gradually diminish as the nutritional requirements of the infant increase. Gray (I98I) and others (Cantrelle and Leridon, 197I; Wray, 1978) have argued that the relative advantages from both the immune and nutritional potential of mother's milk decrease rapidly after the sixth month. The importance of each of these properties for the health of a child depends on conditions that heighten or lower the child's exposure to deleterious factors that can be neutralized by mother's milk (Millman, 1985).

The relationship between breastfeeding and infant and child mortality has been amply documented in studies from many areas of the world. Although the magnitude of the estimates differ from study to study and across cultures, most research in developing countries attest to 
the importance of breastfeeding as a determinant of child survival. In general, the literature indicates that breastfed children are less susceptible to the risk of infant and child death than are artificially fed children. Furthermore, even among breastfed children, both the duration and the intensity of breastfeeding are positively associated with child survival. Thus, wholly breastfed children tend to have a lower risk of dying than partially breastfed ones (Knodel and Kintner, 1977; Da Vanzo et al., 1983; Palloni and Tienda, 1986).

Health care services and the availability of breast milk substitutes have been associated with less initiation of breastfeeding and shorter durations. In urban areas, births to women often occur in hospitals and maternity centres where women are exposed to the practices of trained health personnel and have to contend with established hospital routines. Many health personnel consider infant formula to be as good as, if not better than, breast milk; they influence the mother's view of the adequacy of her breast milk for the child's health (WHO/UNICEF, 198I). In contrast, since provision of health services in many developing countries is concentrated in the urban areas, mothers in rural areas are more likely to deliver at home and are consequently more removed from such influences. Among rural, illiterate families living in unsanitary conditions, mothers who rely on formula often dilute the formula powder with water to such an extent that it inhibits the food value, leading to impaired physical growth and malnutrition of the infant. Also, many of these women lack the proper facilities for sterilizing bottles and nipples or refrigerating mixed formula or milk. The water used to dilute formulas is often unclean, resulting in gastrointestinal disease, one of the major causes of death in infants in developing countries.

Another notable phenomenon in breastfeeding is the age pattern with respect to mortality. Many studies have found that the strong effects of breastfeeding on mortality in the early months of life wane gradually as the child grows older. A study of infant and early childhood mortality in Peru found a negative relationship between breastfeeding and child mortality between I and 23 months of age (Palloni and Tienda, 1986). The results indicate that breastfeeding became less significant as the child grew older.
There remains much to learn, however, regarding the factors underlying the relationship between breastfeeding and infant and child mortality. In fact, the little that is known is derived from clinical and epidemiological evidence that breast milk has some properties that relate to child survival. The claim that breast milk alone may no longer satisfy the nutritional requirements of the child after the sixth month may account in part for the declining importance of breastfeeding after that age that is noted by many studies. It is becoming apparent that supplementation and environmental factors may have a greater impact on infant and child mortality after six months of age.

The Kenya Fertility Survey (KFS, 1977/78) found that most Kenyan women breastfed fully for two months and thereafter tended to supplement breast milk; by the end of two months, $66 \%$ had given supplementary food. So the actual problem in Kenya is not initiation of breastfeeding but the duration and intensity of breastfeeding. The Kenya Rural Child Nutrition Survey (1977/78), found that, on average, mothers in the rural areas breastfed their children for 14 months while urban mothers breastfed for only 10 months.

The Kenya Demographic and Health Survey (1989) found that rural women had longer mean durations of breastfeeding than their urban counterparts. It also found an inverse relationship between education and the mean duration of breastfeeding. This is attributed to the fact that a better educated woman is more likely to work away from home, which makes breastfeeding more difficult.

Eelens (1983) found that in healthy areas in Kenya where malaria is not prevalent, both full and partial breastfeeding reduces mortality. In areas where malaria is rife, only full breastfeeding has any effect on child survival. This suggests that partial breastfeeding in adverse circumstances can contribute only minimal protection against disease and death.

Breastfeeding stands out as a child care index that is consistently found to vary inversely with mortality, especially in the first year of life. UNICEF has been at the forefront in the global promotion of a "child survival revolution" based on what is referred to as the GOBI-FF strategy, an 
acronym for "growth monitoring, oral rehydration therapy for diarrhoea, breastfeeding, immunization, food supplements, and family planning." Despite such an intensive programme, infant and child mortality in Kenya continue to be high, especially in certain regions.

\section{The Setting, Data, and Methodology}

Amagoro Division is in Busia District, western Kenya. Amagoro Division is still experiencing fairly high infant and child mortality despite improvements in health care provision and general socio-economic development in the country. The few studies conducted elsewhere in Kenya have focused mostly on breastfeeding patterns and correlates. These studies have not adequately answered the questions linked to the underlying effects of such breastfeeding practices on infant and child mortality under prevailing socio-economic, environmental, and demographic factors. This study to answer such questions.

This paper is based on a sample survey of 1,030 women from Amagoro Division, aged 15-49 years. The women surveyed had had at least one live birth and also had at least one child under five years of age. The data were collected using a precoded questionnaire. The breastfeeding questions were confined to the closed birth interval (i.e., the second last child) and to the open birth interval (i.e., the last child). Two aspects of breastfeeding practices were examined in the survey: duration of breastfeeding, and age at which supplementary feeding was introduced to the child in addition to or as a substitute for breast milk. These are crucial elements in understanding the thrust of this paper.
Logistic regression was used in analysing the data. This technique measures the likelihood of an event occurring (infant or child death) given certain conditions (predictor variables). Only those children who had stopped breastfeeding or who had died after stopping breastfeeding were included in the analysis. There were 442 last births and 638 next-to-last births included in the analysis.

\section{The Model}

A total of 8 models were designed: 4 for the open interval and 4 for the closed interval. Regrettably, it was not possible to subdivide the children into age groups because of the number of children in each category. But, as Table I shows, the majority of those born both last and next to last died between the ages of $I$ and 2 years (though these reported ages at death could have been affected by age heaping and misreporting). It should be noted that a different age grouping would alter the results slightly. This may point to the fact that more children die of environmental factors rather than from breastfeeding practices, since by age I and above, the children become more exposed to infection through the food they eat, the household sanitary conditions, and the environment in which they play. Table I also shows that a substantial number die between the first and sixth months of life $30.6 \%$ for last births and $24.7 \%$ for next-tolast births). This may indicate the effect of breastfeeding practices; that is, many children who died may have been supplemented much earlier, with the supplementary foods given to them having been contaminated due to environmental factors and preparation habits.

\section{Specification of the model}

The following variables are used in the multivariate logistic regression:

\section{A. Breastfeeding Practices}

I. Breastfeeding Duration (in months):

Dummy variables - $0-12 ; 13-18 ; 19-25 ; 25+$ (coded I if the case, 0 otherwise). 
2. Age at Supplementation (in months)

Dummy variables $-0-3 ; 4-6 ; 7+$ (coded I if the case, 0 otherwise).

B. Environmental Factors

3. Source of Water

Dummy variables - Well; River (coded I if the case, 0 otherwise).

4. Type of Toilet Facility

Dummy variables - Pit; Bush (I if the case, 0 otherwise).

5. Place of Delivery

Dummy variables - Hospital/maternity clinic; Home (I if the case, 0 otherwise).

C. Socio-economic Factors

6. Level of Education

Dummy variables - No Education; Primary and Secondary+ (I if the case, 0 otherwise).

7. Work Status

Dummy variables - Working away from home; Not working ( $\mathrm{I}$ if the case, 0 otherwise).

8. Immunization

Dummy variables - Not immunized; Received some;Completed immunizations ( $I$ if the case, 0 otherwise).

D. Demographic Factors

9. Age of Mother

Dummy variables - I5-24; 25-34; $35+(\mathrm{I}$ if the case, 0 otherwise).

10. Marital Status

Dummy variables - Married; Single ( $\mathrm{I}$ if the case, 0 otherwise).

II. Parity

Dummy variables - I-2; 3-4; 5+ (I if the case, 0 otherwise). 


\section{Logistic Regression Estimates for the Last Births}

A total of 4 models are designed. The first model interprets logistic regression estimates of the impact of breastfeeding duration and age at supplementation on infant and child mortality. The second model introduces environmental factors; the third, socio-economic factors; and the fourth, demographic factors. The idea is to see whether earlier estimates change with the introduction of additional factors, including ones that may confound the effect of breastfeeding on infant and child mortality.

Tables 2, 3 and 4 give the estimates for these models. Model 4 is exceptional in that the results obtained in Model 3 do not change with the introduction of demographic factors. It is evident from Table 2 that age at supplementation and breastfeeding duration are significant in child survival. Supplementing the child at age 4-6 months has an effect of increasing child survival. This may be because supplementing the child's food at the right age may reduce the risk of infection through contaminated food and hence reduce diarrhoeal diseases which can lead to death.

Breastfeeding duration of $13-18$ months is more significant in reducing the chances of death for the children than a duration of $0-12$ months or more than 19 months.

Type of toilet facility is found to be the most significant determinant of infant and child mortality using Model 2 (see Table 3). Those children whose households use the bush for faecal disposal have a higher risk of dying than do those who use pit or flush toilets.

Breastfeeding duration is still significant, though a duration of more than 25 months is not statistically significant. This may be for the same reason as found in Model I, namely, that at this age a child's health status is determined more by the environmental conditions under which he plays, is fed, and lives.

Table 4 shows the results of Model 3, wherein both environmental and socio-economic factors are taken into account. Here the impact of breastfeeding practices becomes completely insignificant. Using the bush as a toilet facility remains very significant, though the pattern and strength of the relationship are reduced with the inclusion of socio-economic factors.

Of the socio-economic factors, only immunization is found to be strongly related to infant and child mortality. The results suggest that there is a negative relationship between immunization and child death. Fully immunized children were significantly less likely to die than those who had received only some immunization or none.

These patterns suggest that the most important determinants of infant and child survival in Amagoro Division are environmental and socioeconomic factors, which usually go hand-in-hand with the level of maternal education. Despite results showing that maternal education was not significant, they point to the fact that children who receive adequate health care and are fully immunized have better chances of survival than those who do not. Many studies have shown that maternal education increases the mother's awareness of the importance of proper nutrition and health care for the children (Caldwell, 1979, 1983; Mott, 1982). Therefore the influence of education may have been overshadowed by the effect of immunization.

Interestingly, the inclusion of demographic factors in Model 4 does not alter the results obtained in Model 3. The pattern and strength of associations found in Model 3 remains unchanged. This shows that age, parity, and marital status of the mother have no significant effect on child survival in Amagoro. Although breastfeeding stands out as very significant, its significance is completely modified by the socio-economic factors. A number of things may account for these findings. One is the problem of heaping in the reported breastfeeding durations, age at supplementation and age at death. The possibility that this can alter the estimated effects of breastfeeding on infant and child mortality has been noted elsewhere (Akin et al., 198I; Palloni and Millman, 1986).

Another possible reason for the breastfeeding results in this study relates to factors that may diminish the advantages of breastfeeding over supplementary feeding. Generally, the impact of 
breastfeeding on infant and child mortality risk depends on the nutritional quality of substitute foods, the sanitary conditions surrounding artificial feeding, and the overall health conditions of the infant's environment (Knodel, 1977: I II3). The issue of supplementary feeding is very important, since the breastfeeding discussed in this study is largely supplemented breastfeeding. In Kenya, as elsewhere in African communities today, the long duration of breastfeeding is punctuated by the early introduction of supplementary foods. For example, about $20 \%$ of the children in the present study had already been introduced to supplementary feeding by the second month of life. By the fourth month, this number had increased to about $70 \%$. The quality of the foods given to a breastfed child may therefore either boost or diminish the child's survival chances. Also, the degree of sanitation involved in food preparation and feeding -- and especially the type of toilet facilities used by the household -- influences the health and mortality status of the child.

Breastfeeding duration remains important. However, a duration of more than 25 months is not statistically significant, perhaps because at this age a child's health status is determined more by the environmental conditions under which he plays, is fed, and lives.

\section{Logistic Regression Estimates for Next to Last Births}

Again, four models are designed, following the same pattern as for last births. The regression results are shown in Tables 5, 6, and 7. Once again, breastfeeding for a period of more than 25 months is not statistically significant. Not only does the child evidently build immunity as he or she grows, but by the age of two years and more the child is prone to environmental health risks such as accidents or parasites. Hence, breastfeeding is less important at this age.

As in the case of the last births, Model 2 introduces the environmental factors. The results of the model are shown in Table 6. The introduction of environmental factors into the model does not greatly alter the results, however. Type of toilet facility does become the most significant predictor of child death, as is the case with Model 2 for last births. Use of the bush for faecal disposal significantly increases the likelihood of dying as compared to using pit/flush toilets.

Once again, supplementing the child's breast milk at age 4-6 months decreases the likelihood of dying. Breastfeeding for more than 25 months reduces the likelihood of dying, although this is not statistically significant.

Model 3 incorporates socio-economic factors. The regression estimates are shown in Table 7. A notable aspect of this Model is that type of toilet facility is no longer a significant predictor of child death when socio-economic factors are included. Furthermore, immunization (complete or partial) becomes the most significant predictor of infant and child death. Complete or partial immunization decreases the likelihood of dying as compared to having received none.

Lastly, the likelihood of child death is positively related to mothers not working. Although level of education is again not itself significant, it has been established that work status is generally related to level of education. Children born to more disadvantaged women in terms of education and health care, for instance, are more susceptible to mortality. But such children tend to breastfeed longer than those born to more advantaged mothers with higher levels of education. It may, therefore, be the case that the effects of maternal socio-economic status far outweigh the advantage of long breastfeeding durations with respect to survival chances among children. Generally, educated women tend to breastfeed less and are likely to introduce supplementary feeding earlier than do those with little or no education. Nevertheless, their educational advantage may enable them to maintain more hygienic child feeding practices and to afford higher quality supplementary foods. Thus, the combined advantages of improved sanitary conditions and higher quality of supplementary foods may override the advantages of breastfeeding even though women may be working away from home.

Once more, the addition of demographic factors fails to alter the results. The estimates remain unchanged and so are exactly the same as those obtained in Model 3. We can conclude that 
demographic factors are not significant predictors of child mortality in Amagoro Division.

\section{DISCUSSION AND CONCLUSION}

This paper has identified several areas that need more research and programme intervention in Busia District in general and in Amagoro Division in particular.

First, the study has shown that duration of breastfeeding significantly influences child mortality. The longer the duration, the higher the chances of survival. However, the study has also noted a decline in breastfeeding duration among educated women. Indeed, education, urbanization, and income are recognized as the principal factors affecting the incidence and duration of breastfeeding, together with the intervening socio-cultural factors such as health services, employment status of women, and availability of breast milk substitutes (Huffman, 1984). As a result, this paper recommends that the government re-train health personnel, especially those in the Maternal and Child Health $(\mathrm{MCH})$ clinics in the division, to educate and train the mothers on advantages of breastfeeding to their children. Furthermore, public awareness on the importance of breastfeeding should be created in the whole country through the mass media. Likewise, the government, nongovernmental organisations, and health workers should encourage the promotion and protection of breastfeeding even during the second year of life. These efforts should include the development of positive societal attitudes toward longer breastfeeding duration.

Second, it was found that the age at which supplementary feeding is introduced to the child influences child survival. In many developing countries, most mothers initiate breastfeeding but introduce breast milk substitutes quite early, with most children receiving some form of supplementation by the fourth month. Here it is recommended that public information, education, and communication be intensified through the appropriate media on the theme that supplementation should start at ages 4-6 months. This may reduce infant and child deaths related to poor child nutrition and feeding habits which are often related to unsanitary conditions.

The paper also recommends that national public health education be intensified to inform the people about the importance of proper sanitation and environmental hygiene, stressing the use of proper toilets. This may reduce the risk of infections related to environmental hygiene and sanitation. It is also recommended that public education about the importance of immunization be intensified by the government and be aimed especially at changing traditional attitudes and practices towards child health.

Work status of the mother is found to influence infant and child mortality. When women are active in income-generating activities, they are likely to have a greater share in household decision-making with respect to expenditures on food, health, and so on. This paper recommends that legislation should be developed and enforced to provide for longer maternity leaves and to enable women who wish to breastfeed in the workplace to do so. Improved child mortality rates must be complemented with activities aimed at improving the living standards of the people, especially income-generating activities for women and improved nutrition.

\section{APPENDIX}

Table I Age at Death, Last Births and Next to Last Births

\begin{tabular}{|c|c|c|c|c|}
\hline \multirow[t]{2}{*}{ Age at Death } & \multicolumn{2}{|c|}{ Last Births } & \multicolumn{2}{|c|}{$\begin{array}{l}\text { Next to Last } \\
\text { Births }\end{array}$} \\
\hline & Number & $\%$ & Number & $\%$ \\
\hline
\end{tabular}




\begin{tabular}{||l|r|r|r|r||}
\hline \hline < I Month & 3 & 6.1 & 7 & 9.6 \\
I Month - 6 Months & 15 & 30.6 & 18 & 24.7 \\
7 Months - < I Year & 7 & 14.3 & 13 & 17.8 \\
I Year - < Years & 19 & 38.8 & 23 & 31.5 \\
$2+$ Years & 5 & 10.2 & 12 & 16.4 \\
\hline \hline Total & 49 & 100.0 & 73 & 100.0 \\
\hline
\end{tabular}

Table 2 Logistic Regression Estimates on the Impact of Breastfeeding and Age at Supplementation on Infant and Child Mortality - Last Births

\begin{tabular}{|c|c|c|c|c|}
\hline \multirow[t]{2}{*}{ Variables } & \multicolumn{4}{|c|}{ Equations } \\
\hline & I & 2 & 3 & 4 \\
\hline \multicolumn{5}{|l|}{ Sup2 } \\
\hline B & -3.1021 & -3.4643 & -2.9460 & -1.2429 \\
\hline Significance & 0.0000 & 0.0000 & 0.0000 & 0.0435 \\
\hline $\operatorname{Exp}(B)$ & 0.0450 & 0.0313 & 0.0526 & 0.2886 \\
\hline \multicolumn{5}{|l|}{ Dur2 } \\
\hline B & & -2.8503 & -3.3739 & -3.6378 \\
\hline Significance & & 0.0001 & 0.0000 & 0.0000 \\
\hline $\operatorname{Exp}(B)$ & & 0.0578 & 0.0343 & 0.0263 \\
\hline \multicolumn{5}{|l|}{ Dur3 } \\
\hline B & & & -3.5975 & -4.345 I \\
\hline Significance & & & 0.0005 & 0.0000 \\
\hline $\operatorname{Exp}(B)$ & & & 0.0274 & 0.0130 \\
\hline \multicolumn{5}{|l|}{ Dur4 } \\
\hline B & & & & -9.1220 \\
\hline
\end{tabular}




\begin{tabular}{||l||l|l||l|l||}
\hline Significance & & & 0.6476 \\
Exp(B) & & & \\
\hline Constant & -1.0761 & -0.5412 & -0.0336 & 0.0689 \\
\hline \hline B & 0.0000 & 0.0047 & 0.8754 & 0.7511 \\
\hline
\end{tabular}

Table 3 Logistic Regression Estimates of the Impact of Breastfeeding Practices and Environmental Factors on Infant and Child Mortality -- Last Births

\begin{tabular}{|c|c|c|c|c|c|}
\hline \multirow[t]{2}{*}{ Variables } & \multicolumn{5}{|c|}{ Equations } \\
\hline & I & 2 & 3 & 4 & 5 \\
\hline \multicolumn{6}{|l|}{ Bush } \\
\hline B & 2.9846 & 2.1553 & 2.1045 & 1.7913 & 1.4732 \\
\hline Significance & 0.0000 & 0.0000 & 0.0000 & 0.0001 & 0.0008 \\
\hline $\operatorname{Exp}(B)$ & 19.779| & 8.6306 & 8.2030 & 5.9974 & 4.3638 \\
\hline \multicolumn{6}{|l|}{ Sup2 } \\
\hline B & & -2.1815 & -2.4883 & -2.0024 & -0.7535 \\
\hline Significance & & 0.0001 & 0.0000 & 0.0010 & 0.2507 \\
\hline $\operatorname{Exp}(B)$ & & 0.1129 & 0.0831 & 0.1350 & 0.4707 \\
\hline \multicolumn{6}{|l|}{ Dur2 } \\
\hline B & & & -2.7577 & -3.1535 & -3.3860 \\
\hline Significance & & & 0.0003 & 0.0000 & 0.0000 \\
\hline $\operatorname{Exp}(B)$ & & & 0.0634 & 0.0427 & 0.0338 \\
\hline \multicolumn{6}{|l|}{ Dur3 } \\
\hline B & & & & $-3.238 I$ & -3.9665 \\
\hline Significance & & & & 0.0019 & 0.0002 \\
\hline $\operatorname{Exp}(B)$ & & & & 0.0392 & 0.0189 \\
\hline
\end{tabular}




\begin{tabular}{|c|c|c|c|c|c|}
\hline \multicolumn{6}{|l|}{ Dur4 } \\
\hline B & & & & & -8.6173 \\
\hline Significance & & & & & 0.6672 \\
\hline $\operatorname{Exp}(B)$ & & & & & 0.0002 \\
\hline \multicolumn{6}{|l|}{ Constant } \\
\hline \multirow{3}{*}{$\begin{array}{l}\text { B } \\
\text { Significance }\end{array}$} & - & - & - & - & - \\
\hline & 3.3440 & 2.2939 & I.759| & 1.1640 & 0.8774 \\
\hline & 0.0000 & 0.0000 & 0.0000 & 0.0020 & 0.0179 \\
\hline
\end{tabular}

Table 4 Logistic Regression Estimates of the Impact of Breastfeeding Practices, Environmental and Socio-economic Factors on Infant and Child Mortality - Last Births

\begin{tabular}{|c|c|c|c|}
\hline \multirow[t]{2}{*}{ Variables } & \multicolumn{3}{|c|}{ Equations } \\
\hline & I & 2 & 3 \\
\hline \multicolumn{4}{|l|}{ Bush } \\
\hline B & 2.9846 & 1.9125 & 1.0216 \\
\hline Significance & 0.0000 & 0.0000 & 0.0198 \\
\hline $\operatorname{Exp}(B)$ & 19.779| & 6.7699 & 2.7777 \\
\hline \multicolumn{4}{|l|}{ Comp } \\
\hline B & & -4.0814 & -5.0383 \\
\hline Significance & & 0.0001 & 0.0000 \\
\hline $\operatorname{Exp}(B)$ & & 0.0169 & 0.0065 \\
\hline \multicolumn{4}{|l|}{ Some } \\
\hline B & & & -9.6835 \\
\hline Significance & & & 0.6476 \\
\hline $\operatorname{Exp}(B)$ & & & 0.0001 \\
\hline Constant & & & \\
\hline
\end{tabular}




\begin{tabular}{|l|l|l|l||}
\hline \hline B & -3.3440 & -1.8742 & -0.7166 \\
Significance & 0.0000 & 0.0000 & 0.0478 \\
\hline
\end{tabular}

Table 5 Logistic Regression Estimates of the Impact of Breastfeeding Practices and Age at Supplementation on Infant and Child Mortality -- Next to Last Births

\begin{tabular}{|c|c|c|c|c|}
\hline \multirow[t]{2}{*}{ Variables } & \multicolumn{4}{|c|}{ Equations } \\
\hline & I & 2 & 3 & 4 \\
\hline \multicolumn{5}{|l|}{ Sup2 } \\
\hline B & -3.6325 & -3.1708 & -3.4045 & -2.1496 \\
\hline Significance & 0.0000 & 0.0000 & 0.0000 & 0.0001 \\
\hline $\operatorname{Exp}(B)$ & 0.0265 & 0.0420 & 0.0332 & 0.1165 \\
\hline \multicolumn{5}{|l|}{ Dur3 } \\
\hline B & & -2.9350 & -3.6994 & $-4 .|3| 1$ \\
\hline Significance & & 0.0001 & 0.0000 & 0.0000 \\
\hline $\operatorname{Exp}(B)$ & & 0.0531 & 0.0247 & 0.0161 \\
\hline \multicolumn{5}{|l|}{ Dur2 } \\
\hline B & & & - & -2.8243 \\
\hline & & & 0.0000 & 0.0000 \\
\hline $\operatorname{Exp}(B)$ & & & 0.0763 & 0.0594 \\
\hline \multicolumn{5}{|l|}{ Dur4 } \\
\hline B & & & & -8.8387 \\
\hline Significance & & & & 0.6255 \\
\hline $\operatorname{Exp}(B)$ & & & & 0.0001 \\
\hline \multicolumn{5}{|l|}{ Constant } \\
\hline B & -0.9420 & -0.5761 & 0.2197 & 0.3878 \\
\hline
\end{tabular}




\begin{tabular}{|l|l|l|l|l|}
\hline Significance & 0.0000 & 0.0002 & 0.2510 & 0.0501 \\
\hline
\end{tabular}

Table 6 Logistic Regression Estimates of the Impact of Breastfeeding Practices and Environmental Factors on Infant and Child Mortality -- Next to Last Births

\begin{tabular}{|c|c|c|c|c|c|}
\hline \multirow[t]{2}{*}{ Variables } & \multicolumn{5}{|c|}{ Equations } \\
\hline & I & 2 & 3 & 4 & 5 \\
\hline \multicolumn{6}{|l|}{ Bush } \\
\hline B & 2.6534 & I.679| & 1.4986 & I.289| & I. 1288 \\
\hline Significance & 0.0000 & 0.0000 & 0.0000 & 0.0002 & 0.0013 \\
\hline $\operatorname{Exp}(B)$ & 14.2029 & 5.3606 & 4.4755 & 3.6295 & 3.0919 \\
\hline \multicolumn{6}{|l|}{ Sup2 } \\
\hline B & & -2.9615 & -2.5094 & -2.8053 & $-|.850|$ \\
\hline Significance & & 0.0000 & 0.0000 & 0.0000 & 0.0015 \\
\hline $\operatorname{Exp}(B)$ & & 0.0517 & 0.0813 & 0.0605 & 0.1572 \\
\hline \multicolumn{6}{|l|}{ Dur3 } \\
\hline B & & & -2.7179 & -3.4322 & -3.8448 \\
\hline Significance & & & 0.0002 & 0.0000 & 0.0000 \\
\hline $\operatorname{Exp}(B)$ & & & 0.0660 & 0.0323 & 0.0214 \\
\hline \multicolumn{6}{|l|}{ Dur2 } \\
\hline B & & & & -2.4331 & -2.6546 \\
\hline Significance & & & & 0.0000 & 0.0000 \\
\hline $\operatorname{Exp}(B)$ & & & & 0.0878 & 0.0703 \\
\hline \multicolumn{6}{|l|}{ Dur4 } \\
\hline B & & & & & -8.5528 \\
\hline Significance & & & & & 0.6337 \\
\hline $\operatorname{Exp}(B)$ & & & & & 0.0002 \\
\hline
\end{tabular}




\begin{tabular}{||l||l|l|l|l|l||}
\hline \hline Constant \\
\hline \hline B & -3.0589 & -1.8076 & - & - & -0.2824 \\
Significance & 0.0000 & 0.0000 & 1.3919 & 0.5314 & \\
& & & 0.0000 & 0.0616 & 0.3301 \\
\hline
\end{tabular}

Table 7 Logistic Regression Estimates on the Impact of Breastfeeding Practices, Environmental and Socio-economic Factors on Infant and Child Mortality -- Next to Last Births

\begin{tabular}{|c|c|c|c|c|c|c|c|}
\hline \multirow[t]{2}{*}{ Variables } & \multicolumn{7}{|c|}{ Equations } \\
\hline & I & 2 & 3 & 4 & 5 & 6 & 7 \\
\hline \multicolumn{8}{|l|}{ Comp } \\
\hline $\begin{array}{l}\text { B } \\
\text { Significance } \\
\text { Exp(B) }\end{array}$ & $\begin{array}{l}- \\
5.9223 \\
0.0000 \\
0.0027\end{array}$ & $\begin{array}{l}- \\
6.5132 \\
0.0000 \\
0.0015\end{array}$ & $\begin{array}{l}- \\
6.7792 \\
0.0000 \\
0.0011\end{array}$ & $\begin{array}{l}6.1261 \\
0.0000 \\
0.0022\end{array}$ & $\begin{array}{l}- \\
5.4635 \\
0.0000 \\
0.0042\end{array}$ & $\begin{array}{l}- \\
5.5220 \\
0.0000 \\
0.0040\end{array}$ & $\begin{array}{l}-5.6792 \\
0.0000 \\
0.0034\end{array}$ \\
\hline \multicolumn{8}{|l|}{ Some } \\
\hline $\begin{array}{l}\text { B } \\
\text { Significance } \\
\text { Exp(B) }\end{array}$ & & $\begin{array}{l}3.4012 \\
0.0000 \\
0.0333\end{array}$ & $\begin{array}{l}- \\
3.6938 \\
0.0000 \\
0.0249\end{array}$ & $\begin{array}{l}- \\
2.994 I \\
0.0002 \\
0.0501\end{array}$ & $\begin{array}{l}- \\
2.5119 \\
0.0024 \\
0.0811\end{array}$ & $\begin{array}{l}- \\
2.6939 \\
0.0013 \\
0.0676\end{array}$ & $\begin{array}{l}-1.9081 \\
0.0007 \\
0.0546\end{array}$ \\
\hline \multicolumn{8}{|l|}{ Dur2 } \\
\hline $\begin{array}{l}\text { B } \\
\text { Significance } \\
\text { Exp(B) }\end{array}$ & & & $\begin{array}{l}- \\
2.0188 \\
0.0000 \\
0.1328\end{array}$ & $\begin{array}{l}- \\
2.4440 \\
0.0000 \\
0.0868\end{array}$ & $\begin{array}{l}- \\
2.5438 \\
0.0000 \\
0.0786\end{array}$ & $\begin{array}{l}2.7620 \\
0.0000 \\
0.0632\end{array}$ & $\begin{array}{l}-2.9901 \\
0.0000 \\
0.0563\end{array}$ \\
\hline \multicolumn{8}{|l|}{ Dur3 } \\
\hline $\begin{array}{l}\text { B } \\
\text { Significance }\end{array}$ & & & & $\begin{array}{l}- \\
2.9693\end{array}$ & $-\overline{2.6759}$ & $-\overline{2.8620}$ & $\begin{array}{l}-2.7749 \\
0.0011\end{array}$ \\
\hline
\end{tabular}




\begin{tabular}{|c|c|c|c|c|c|c|c|}
\hline $\operatorname{Exp}(B)$ & & & & $\begin{array}{l}0.0002 \\
0.0513\end{array}$ & $\begin{array}{l}0.0011 \\
0.0688\end{array}$ & $\begin{array}{l}0.0006 \\
0.0572\end{array}$ & 0.0624 \\
\hline \multicolumn{8}{|l|}{ Sup2 } \\
\hline $\begin{array}{l}\text { B } \\
\text { Significance } \\
\text { Exp(B) }\end{array}$ & & & & & $\begin{array}{l}- \\
1.8225 \\
0.0057 \\
0.1616\end{array}$ & $\begin{array}{l}\overline{1} \\
0.8359 \\
0.0066 \\
0.1595\end{array}$ & $\begin{array}{l}-2.0605 \\
0.0030 \\
0.1274\end{array}$ \\
\hline \multicolumn{8}{|l|}{ No } \\
\hline $\begin{array}{l}\text { B } \\
\text { Significance } \\
\text { Exp(B) }\end{array}$ & & & & & & $\begin{array}{l}2.1982 \\
0.0191 \\
9.0091\end{array}$ & $\begin{array}{l}2.4664 \\
0.0101 \\
11.7802\end{array}$ \\
\hline \multicolumn{8}{|l|}{ Sup3 } \\
\hline $\begin{array}{l}\text { B } \\
\text { Significance } \\
\text { Exp(B) }\end{array}$ & & & & & & & $\begin{array}{l}-1.8220 \\
0.0224 \\
0.1617\end{array}$ \\
\hline \multicolumn{8}{|l|}{ Constant } \\
\hline $\begin{array}{l}\text { B } \\
\text { Significance }\end{array}$ & $\begin{array}{l}- \\
0.2342 \\
0.1376\end{array}$ & $\begin{array}{l}0.3567 \\
0.0555\end{array}$ & $\begin{array}{l}0.8531 \\
0.0002\end{array}$ & $\begin{array}{l}1.2588 \\
0.0000\end{array}$ & $\begin{array}{l}1.4794 \\
0.0000\end{array}$ & $\begin{array}{l}- \\
0.4943 \\
0.5773\end{array}$ & $\begin{array}{l}- \\
0.4787 \\
0.5910\end{array}$ \\
\hline
\end{tabular}

\section{REFERENCES}

- $\quad$ Akin, J.S.; R.E. Bilsborrow; D.K. Guilkey and B.M. Popkin (1986). "Breast-feeding Patterns and Determinants in the Near East: Analysis for four countries." Population Studies 40: 247262.

- Barros, F. \& C.G. Victora, (1990). Breastfeeding and Diarrhoea in Brazilian Children. The Population Council. New York.
- Buchanan R., (1975). "Breastfeeding: Aid to Infant Health and Fertility Control". Population Report Series J, No.4, July 1975. George Washington University Medical Center, Washington, D.C.

- Caldwell, J.C. (1983). "Introductory remarks on the interaction between health, mortality and development," in U.N. (1984) Mortality and Health Policy.

- Caldwell, J.C (1979). "Education as a factor of mortality decline: An 
examination of Nigerian data". Population Studies 33: 388-402.

- Cantrelle P. \& Leridon H. (197I). "Breastfeeding mortality in childhood and fertility in a rural zone of Senegal." Population Studies 25: 505-533.

- Da Vanzo, J; Butz W.P. and J. P. Habicht (1983). "How biological and behavioral influences on mortality in Malaysia vary during the first year of life." Population Studies 37: 38I-402.

- Eelens, Frank (1983). "The impact of breastfeeding on infant and child mortality with varying incidence of malaria - Evidence from the Kenya Fertility Survey 1977-78." Interuniversity Programme in Demography. Working Paper 1983-3.

- Gray, R.H. (198I). "Birth intervals, postpartum sexual abstinence and child health," in H. Page and R. Lesthaeghe (eds.), Child spacing in Tropical Africa: Traditions and Change. New York: Academic Press.

- Huffman, S.L. (1984). "Determinants of breastfeeding in developing countries: overviews and policy implications." Studies in Family Planning I5(4): I70-I84.

- Kenya, Republic of (1989). Busia District Development Plan 1989-93. Ministry of Planning and National Development.

- Kenya, Republic of (1978). Kenya Rural Child Nutrition Survey, 1977/78. Country Report. Central Bureau of Statistics. Ministry of Economic Planning and Development. Nairobi, Kenya.

- Kenya, Republic of (1978). Kenya Fertility Survey, 1977/78. Country Report. Central Bureau of Statistics. Ministry of Economic Planning and Development. Nairobi, Kenya.

- Kleinman, R. L. (ed.) (1984). "Breastfeeding: Fertility and Contraception." IPPF Medical Publication, England.
- Knodel, J. (1977). "Breastfeeding and Population Growth". Science 198: IIIIIII5.

- Knodel, J. \& H. Kintner (1977). "The impact of breastfeeding patterns of the biometric analysis of infant mortality." Demography 14(4): 39 I-409.

- Millman, S. (1985). "Breastfeeding and Contraception: Why the inverse association?" Studies in Family Planning I6(2): 6I-75.

- Mott, E.L. (1982). "Infant mortality in Kenya: Evidence from the Kenya fertility survey," WFS Scientific Reports No. 32, International Statistical Institute, Voorburg, Netherlands.

- NCPD \& IRD (1989). Kenya Demographic Health Survey, 1989. Country Report. National Council for Population and Development. Ministry of Home Affairs and National Heritage. Nairobi, Kenya.

- Palloni, A. \& M. Tienda (1986). "The effects of breastfeeding and pace of child bearing on mortality at early ages." Demography 23(I): 3 I-52.

- Palloni, A \& S. Millman (1986). "The effects of inter-birth intervals and breastfeeding on infant and early childhood mortality." Population Studies 40: 215-236.

- W.H.O./U.N.I.C.E.F. (I98I). Infant and young child feeding: Current Issues. Geneva: World Health Organization.

- W.H.O. (1979). Preliminary report of the W.H.O. collaborative study on breastfeeding. $\mathrm{MCH} / 79.3$. Geneva, World Health Organization.

- Winikoff, B. (1980). "Weaning, Nutrition, Morbidity and Mortality Consequences". Paper presented at the IUSSP conference in Fiuggi Terme, Italy.

- Wray, J.D. (1978). "Maternal nutrition, breastfeeding and infant survival," in W. Henry Mosley (ed.), Nutrition and Human Reproduction. New York: Plenum Press. 